\title{
3D Paper-based Electrochemical Device Using Graphite Screen Printed Electrode Modified with MIP for Serotonin Detection
}

\author{
Maliwan Amatatongchai ${ }^{1 *}$, Jirayu Sitanurak, Nongyoa Nontawong ${ }^{1}$, \\ Wongduan Sroysee ${ }^{1}$, Purim Jarujamrus ${ }^{1}$ and Peter A. Lieberzeit ${ }^{2}$ \\ ${ }^{1}$ Ubon Ratchathani University, Faculty of Science, Department of Chemistry and Center \\ of Excellence for Innovation in Chemistry, Ubon Ratchathani, 34190, Thailand. \\ ${ }^{2}$ University of Vienna, Faculty for Chemistry, Department of Physical Chemistry, \\ 1090 Vienna, Austria. \\ *maliwan.a@ubu.ac.th
}

\begin{abstract}
:
This paper demonstrates a three-dimensional electrochemical paper-based analytical device (3DePAD) for highly sensitive and selective determination of serotonin. The device was fabricated by alkyl ketene dimer (AKD)-inkjet printing of a circular hydrophobic zone on filter paper for sensing in aqueous samples. This was followed by screen-printing electrodes onto the paper, which was folded underneath hydrophobic zone. A self-assembled three-electrode system, comprising a graphite paste modified with nanoparticles coated with molecularly imprinted polymer (MIP) was fabricated on the patterned paper by screen printing through the pre-designed transparent film slit. A novel core-shell composite of goldcoated magnetite $\left(\mathrm{Fe}_{3} \mathrm{O}_{4} @ \mathrm{Au}\right)$ and $\mathrm{SiO}_{2}$ MIP was synthesized by sol-gel method using serotonin as template molecule, phenyl trimethoxysilane (PTMOS) as monomer, and tetramethoxysilane (TMOS) as cross linker. The three electrodes of modified graphite electrodes ( $\left.\mathrm{Fe}_{3} \mathrm{O}_{4} @ \mathrm{Au} @ \mathrm{SiO}_{2}-\mathrm{MIP} / \mathrm{GFE}\right)$ on the layout paper served as the working electrode, the reference electrode, and the counter electrode, respectively. The fabricated 3D-ePAD was applied to detect serotonin by cyclic voltammetry in $0.1 \mathrm{M}$ phosphate buffer, $\mathrm{pH}=8.0$. Results indicate that the developed device is highly sensitive to serotonin. The oxidation of serotonin was found at $+0.34 \mathrm{~V}$. The anodic peak currents of serotonin provides the linearity ranged from 0.5 to $10 \mu \mathrm{M}\left(\mathrm{y}=0.0224 \mathrm{x}+0.0722, \mathrm{r}^{2}=0.994\right)$. These results demonstrate that our 3D-ePAD have many advantages such as an easy to-use, inexpensive, sensitive, and high selective for serotonin determination.
\end{abstract}

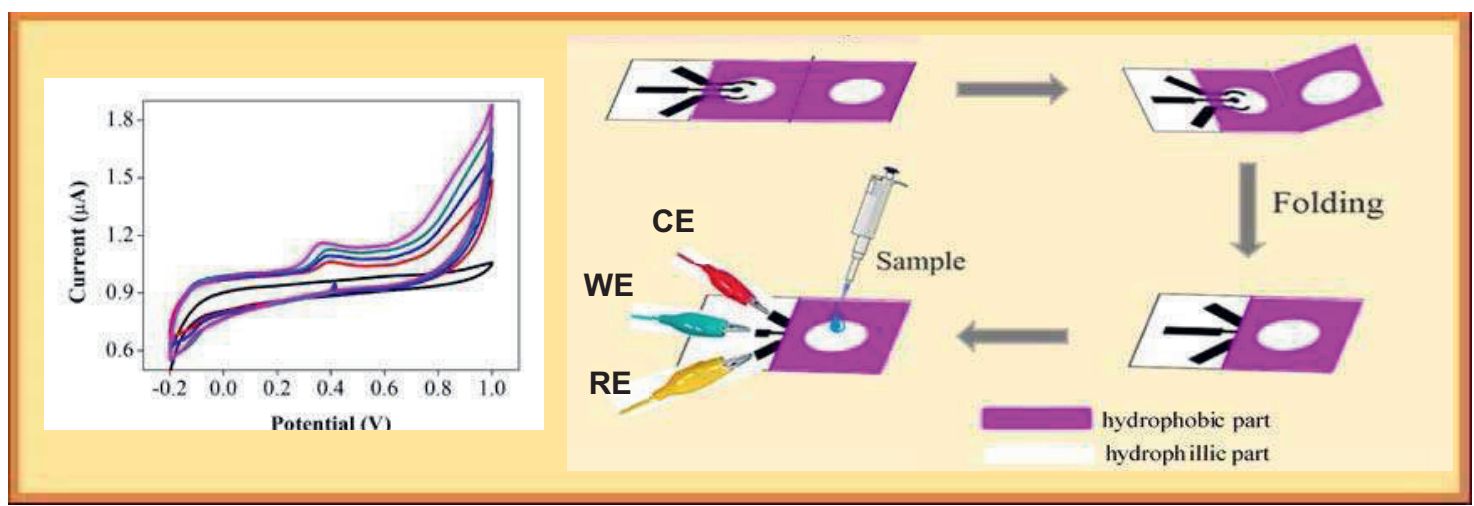

Key words: Serotonin, 3D-electrochemical paper-based analytical device (3D-ePAD), MIP, goldcoated magnetite 